This item was submitted to Loughborough's Research Repository by the author.

Items in Figshare are protected by copyright, with all rights reserved, unless otherwise indicated.

\title{
Comparison of fuel consumption and fuel cell degradation using an optimised controller
}

PLEASE CITE THE PUBLISHED VERSION

http://dx.doi.org/10.1149/07101.0085ecst

\section{PUBLISHER}

(C) The Electrochemical Society

\section{VERSION}

AM (Accepted Manuscript)

\section{PUBLISHER STATEMENT}

This work is made available according to the conditions of the Creative Commons Attribution-NonCommercialNoDerivatives 4.0 International (CC BY-NC-ND 4.0) licence. Full details of this licence are available at: https://creativecommons.org/licenses/by-nc-nd/4.0/

\section{LICENCE}

CC BY-NC-ND 4.0

\section{REPOSITORY RECORD}

Fletcher, Thomas P., R.H. Thring, Martin Watkinson, and lain Staffell. 2016. "Comparison of Fuel Consumption and Fuel Cell Degradation Using an Optimised Controller". figshare. https://hdl.handle.net/2134/22879. 


\title{
Comparison of Fuel Consumption and Fuel Cell Degradation using an Optimised Controller
}

\author{
T. Fletcher ${ }^{\mathrm{a}}$, Prof. R.H. Thring ${ }^{\mathrm{a}}$, M. Watkinson ${ }^{\mathrm{b}}$, Dr I. Staffell ${ }^{\mathrm{c}}$ \\ a Loughborough University, Loughborough, Leicestershire, LE11 3TU, UK \\ b Horiba MIRA, Watling Street, Nuneaton, Warwickshire, CV10 0TU, UK \\ c Imperial College London, London, SW7 2AZ, UK
}

\begin{abstract}
The Energy Management Strategy (EMS) of any hybrid vehicle is responsible for determining the operating state of many components on board the vehicle and therefore has significant effect on the fuel economy, emissions, ageing of components and vehicle drive-ability. It is generally accepted that Stochastic Dynamic Programming (SDP) can be used to produce a near-optimal control strategy provided that an accurate Markov model of the drive-cycle is available, and the cost function used for the optimisation is representative of the true running cost of the vehicle. The vast majority of research in this field focussing solely on the optimisation of the fuel economy, however for a fuel cell hybrid vehicle, the degradation of the fuel cell contributes significantly to the overall running cost of the vehicle, and should therefore be included in calculation of the running cost during the optimisation process. In this work, an optimised controller using SDP is developed for a campus passenger vehicle in order to minimise the lifetime cost of both fuel consumption and fuel cell degradation. The vehicle is then simulated over a number of typical journeys obtained from data logging during its use on the University of Birmingham's campus. It is shown that the expected lifetime cost due to fuel cell degradation massively outweighs the cost of the fuel consumed.
\end{abstract}

\section{Introduction}

\section{$\underline{\text { Motivation }}$}

The automotive industry is currently under great pressure from governments and from consumers to improve vehicle fuel economy and reduce emissions due to climate change, energy security and limited fossil fuel resources. This has lead to massive improvements in conventional powertrain efficiency due to refinements in the design of the Internal Combustion Engine (ICE), but diminishing returns mean that the industry is beginning to introduce alternative powertrain concepts such as hybrid and electric vehicles. One of these designs is the Fuel Cell Hybrid Electric Vehicle (FCHEV) which has the potential to represent a step change in the market with regards to emissions. FCHEVs have the potential to become a truly emission free vehicle, utilising spare capacity from intermittent solar and wind generation facilities. In addition to this, they also use a renewable energy storage medium which can be produced almost anywhere it is required. FCHEVs have recently been introduced to the market by Toyota and Hyundai in limited numbers, but a number of obstacles currently prohibit wide scale commercialisation. 
One of the main obstructions is the high cost of fuel cell systems. Fuel cells are estimated as costing well over $\$ 50 / \mathrm{kW}$ (under mass production) [1] compared to a US Department of Energy (DoE) target of approximately $\$ 35 / \mathrm{kW}[2]$ in order to become competitive with ICEs. Adding this this, the reliability of fuel cells is also currently below the 5000 hours of service target from the DoE for transport applications. This means the overall lifetime cost of running a FCHEV is not yet competitive with conventional powertrain designs.

The reliability of a fuel cell stack depends to a large degree on how it is used $[3,4]$. Certain actions, such as frequent start-stop cycling and high current loading can significantly reduce the lifetime of the stack [4,5], and therefore it is important to consider fuel cell degradation when designing the Energy Management Strategy (EMS). The EMS is responsible for choosing the operating point of the fuel cell in order to optimise the power flow on board a hybrid vehicle and in doing so maintain the battery state of charge. The optimisation of an Energy Management Strategy (EMS) seeks to maximise the benefits afforded by inclusion of an energy storage medium on board a hybrid electric vehicle. Some of these benefits are immediately obvious, such as the ability to re-capture kinetic energy which would otherwise be lost as heat during braking. However, further gains can be made by optimising the operating points of various components in the vehicle in order to maximise the efficiency of the system in a holistic sense [6-8]. As with many optimisation problems there is often degree of "trade-off" between various targets which may include fuel consumption, emissions, drive-ability and component degradation.

Generally, research into the EMS for FCHEVs focusses solely on fuel consumption, which is often used in cost functions due to it's quantitative nature $[9,10]$. Component ageing and associated lifetime costs are often largely overlooked however. The ageing of the battery is often only included in the constraints of the optimisation, and the degradation of the fuel cell is generally ignored completely. Due to the high cost of the fuel cell stack and it's sensitivity to the operating conditions determined by the EMS, the degradation of the fuel cell should be included in the cost function in order to maximise it's useful lifetime. This can be done by weighting the fuel consumption and the estimated degradation by their respective monetary values. Using this as the basis for the cost function, the optimisation will seek to minimise the overall running cost of the vehicle, not only improving fuel consumption, but also the lifetime of the fuel cell.

\section{$\underline{\text { Prior Literature }}$}

There is a great deal of research in the literature with regards to EMS optimisation for many types of hybrid systems including ICE hybrid electric vehicles [10-16], FCHEVs [7, 17-19], aerial vehicles [20], and even static applications, such as off grid hybrid energy supplies [21]. Essentially, for any of these applications, the problem is the same; how best to utilise the multiple power sources in order to maximise the efficiency of the system as whole. As a result, there have been many different techniques that have been demonstrated, starting from "rule-based" algorithms $[17,22]$ to more advanced optimisation techniques such as Deterministic Dynamic Programming (DDP) [6, 23, 24], Equivalent Consumption Minimization Strategy (ECMS) [25-28], Fuzzy Logic [7,21, 29], Neural Networks [20,30], and Game Theory [10], but the most promising technique appears to be Stochastic Dynamic Programming (SDP). 
SDP has been a very popular technique [13-16] over the past few years due to the fact that it is able to produce a near-optimal controller that is both causal and time-invariant and hence can be used on-board a vehicle for real-time control. It's first proposal for a solution to the EMS problem is usually credited to Lin et al. [31] who found that the it outperformed their sub-optimal rule-based strategy based on DDP results. Since 2004, SDP techniques have been gradually refined by the use of more complex models, improved cost functions to include emissions [12], drive-ability [13] and battery degradation [14] and improved solving algorithms such as "terminal state" SDP [12].

The second area of research relevant to this work is the degradation of fuel cells. There is a large volume of research concerning the degradation of fuel cells ranging from detailed electrochemical modelling [32] to empirical work on accelerated ageing testing $[4,33]$. A number of reasons for fuel cell degradation have been identified including degradation of catalyst layer ("Electro-Chemical Active Surface Area (ECASA)" reduction) [4,33], membrane chemical attack [4,33], hydrothermal mechanic stress on the membrane [34] and thermal degradation of the membrane [4,35-37].

The fuel cell controller on the vehicle can limit these degradation methods by managing the reactant pressures, humidity and temperature of the fuel cell. However, it has no control over the demanded power and simply manages the fuel cell reactively depending how the fuel cell is being used. The demanded power has a large effect on some of the degradation causes. For example, demanding high current for a long periods of time may cause the temperature of the fuel cell to increase, and running at very low current and hence high cell potentials can cause electrochemical oxidation of impurities in the fuel. This means that the EMS can have significant effect on the lifetime of the fuel cell. Many of the underlying causes of these degradation methods can be mitigated by;

1. Ensuring fuel cell is electrically loaded when running in order to limit ECASA reduction $[4,38]$

2. Limiting start-up/shut-down cycling where possible to prevent non-uniform distribution of fuel $[4,38]$

3. Avoiding excessive load cycling to prevent humidity changes leading to macroscopic holes in the membrane [34]

4. Ensuring current demand does not exceed reactant supply limitations to prevent reactant starvation [35]

5. Reducing loading if fuel cell temperature is too high to prevent hydrothermal mechanical stress on the membrane [4] 


\section{Cost Function}

The objective of the SDP optimisation is choose actions in order to minimise a future anticipated cost. This cost is calculated by the use of a cost function. In order to minimise the total running cost of the fuel cell, the cost function should include not only the fuel consumption, but also the degradation of the fuel cell. The fuel consumption and degradation can then be "traded off" by changing the weighting parameters. The fuel consumption is simply calculated as a function of the fuel cell power, see Equation 1. This data has been obtained from the equipment data-sheet and verified through preliminary testing of the vehicle.

$$
C_{\text {fuel }}=f\left(P_{F C}\right)
$$

The ageing of the fuel cell is harder to quantify. Testing by the fuel cell manufacturer specifies a maximum number of start/stop cycles, $n_{\max }$, which is likely to correspond to degradation method (2). The fuel cell should also be shut down when electrically unloaded in order to prevent ageing due to degradation method (1). Combining these facts, Equation 2 has been derived, which penalises the EMS each time the fuel cell demand power drops to $0 \mathrm{~W}$. The manufacturer has also found through testing that dynamic loads "including instantaneous load changes between idle and full power" result in no performance degradation, see Equation 3. Finally, the data-sheet also specifies a maximum lifetime, $t_{\max }$, when running at rated power, but reports essentially "zero" degradation at loads below approximately $80 \%$. This is most likely due to degradation methods (4) and (5) identified in the literature (see Section 1.2). It can therefore be assumed that between these loads, the degradation rate is approximately linear, see Equation 4. It has been assumed that each of the degradation methods is independent and represents a certain drop in cell performance. This allows the degradation due to each method to be summed together to obtain the total degradation of the fuel cell, Equation 5.

$$
\begin{aligned}
& C_{\text {deg } 1,2}= \begin{cases}\frac{1}{n_{\max }}, & \text { if } P_{F C, t+1}>0 \wedge P_{F C, t}=0 \\
0, & \text { otherwise }\end{cases} \\
& C_{\text {deg } 3}= 0 \\
& C_{\text {deg } 4,5}= \begin{cases}\frac{1}{t_{\max }} \times \frac{P_{F C}-0.8 P_{\max }}{0.2 P_{\max }}, & \text { if } P_{F C}>80 \% P_{\max } \\
0, & \text { otherwise }\end{cases} \\
& C_{\text {deg }}=C_{\text {deg } 1,2}+C_{\text {deg } 3}+C_{\text {deg } 4,5}
\end{aligned}
$$

In addition to minimising the total running cost of the fuel cell, the EMS is also responsible for managing the battery. This can be accomplished by setting constraints on the battery voltage which will prevent the battery from becoming over-charged or deeply discharged. By using the battery voltage, rather than state of charge directly, the battery will also be protected from voltage spikes during regenerative braking and from voltage drops during periods of high current demand, such as acceleration. This has been achieved by assigning a cost to extreme cell potentials $\left(V_{\max }\right.$ and $\left.V_{\min }\right)$, Equation 6 . Finally, in order to promote charge sustaining behaviour, an additional cost when transitioning to the terminal 
state can be included, Equation 7. This penalises deviation from the target State of Charge (SoC), $S o C_{T}$, only on the final time step. This cost is not applied at any other time meaning that the battery $\mathrm{SoC}$ is allowed to fluctuate throughout the cycle as long as it recovers by the end of the journey.

$$
\begin{gathered}
C_{V}= \begin{cases}\int\left(V_{\text {min }}-V_{b a t}\right) d t, & \text { if } V_{b a t}<V_{\text {min }} \\
\int\left(V_{b a t}-V_{\text {max }}\right) d t, & \text { if } V_{b a t}>V_{\text {max }} \\
0, & \text { otherwise }\end{cases} \\
C_{S o C}=\left(\mathrm{SoC}-\mathrm{SoC}_{T}\right)^{2}
\end{gathered}
$$

The final cost function, Equation 8, is made up by weighting and summing the individual costs of the fuel, the fuel cell degradation, the battery voltage constraint and the state of charge constraint. The fuel and fuel cell are weighted by their respective monetary values, $V_{\text {fuel }}$ and $V_{F C}$, in order to calculate the estimated total running cost. The battery constraints are assigned weighting parameters $\alpha$ and $\beta$, orders of magnitude higher. This means that the optimisation will avoid states that trigger these costs whenever possible.

$$
C_{\text {total }}=-\left(C_{\text {fuel }} V_{\text {fuel }}+C_{\text {deg }} V_{F C}+\alpha C_{V}+\beta C_{S o C}\right)
$$

\section{Methodology}

The generation of the optimised control strategy has a number of stages. Firstly a stochastic model of the vehicle's usage must be created. This model can then be used in combination with simulation models to calculate the probability and cost of transitioning between different states as defined by the vehicle's speed, acceleration, battery SoC and fuel cell power output. Once the probability and cost of each transition is calculated, SDP is used to calculate the optimal control action to perform in each state in order to minimise the cost function over an infinite horizon. This strategy can then be tested in simulation or on a vehicle to see how it performs.

\section{Markov Chain Drive-Cycle Model}

In order to produce the optimised controller, firstly a stochastic model typical of the vehicle's usage pattern must be generated. This has been achieved by examining a large number of journeys logged while the vehicle was used for transport of passengers and mail at the University of Birmingham [39]. These data are used to generate a Markov chain which maps the probability distribution of the acceleration over the next time step to the vehicles current state as defined by it's current speed and acceleration. This Markov chain also contains a terminal state which represents the end of the journey. 


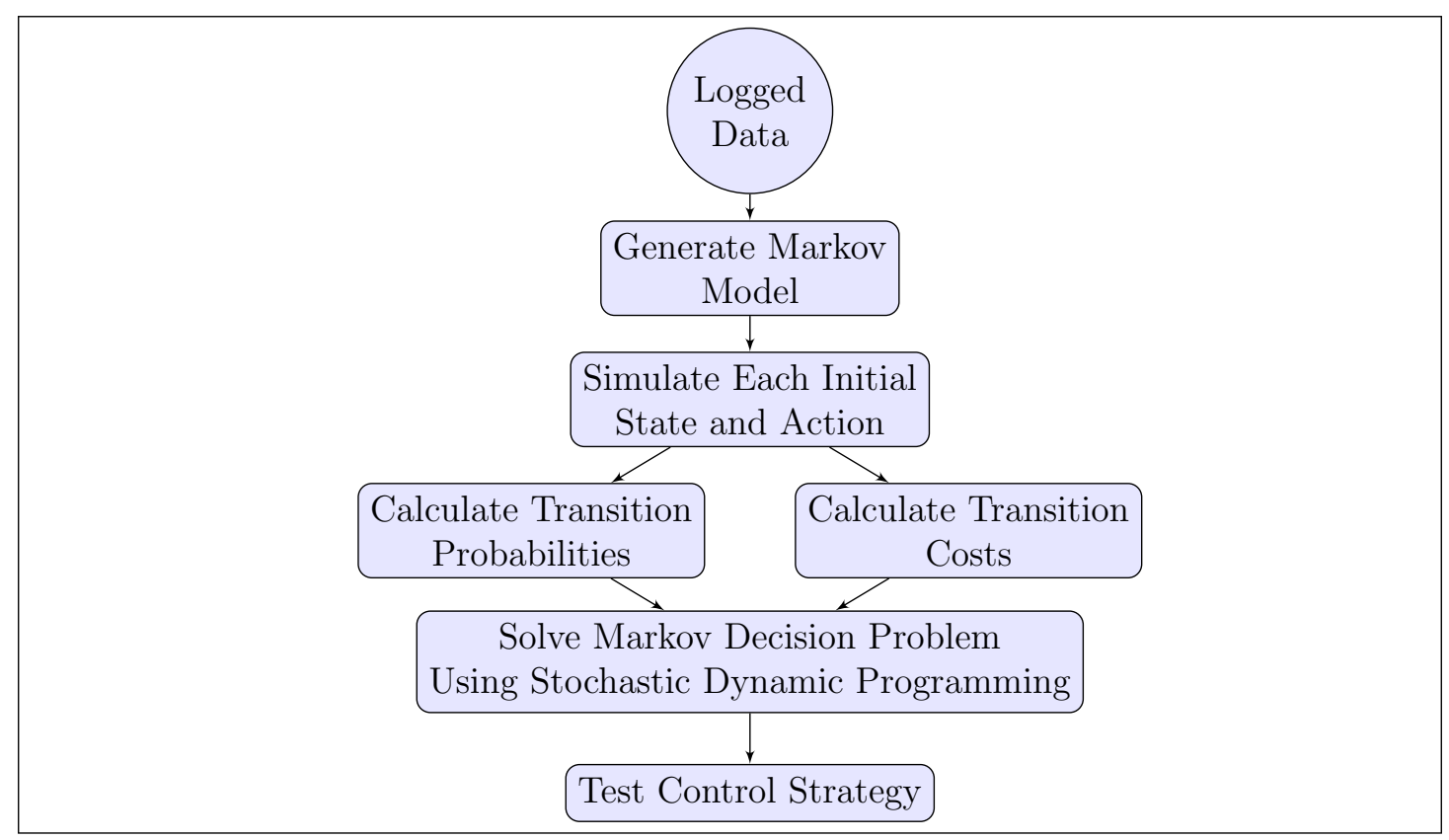

Figure 1: Flowchart of the procedure used to generate real-time controller

\section{Markov Decision Process (MDP) Problem Formulation}

A Markov Decision Process (MDP) problem can be defined by a set of decision epochs, $T$, a set of Actions, $A_{s}$, a set of States, $S$, the probabilities of transitioning between each state, $P_{a, i j}$, and the reward or cost of each transition $C_{a, i j}$. The sample rate of the logged data is 1 second. This is acceptable to use for the MDP problem, any dynamic effects greater than this can be reasonably ignored [31]. The set of actions chosen determines the output power of the fuel cell system (10).

$$
\begin{aligned}
T & =\{0,1, \ldots\} \mathrm{s} \\
A_{s} & =P_{F C}=\left\{0, \ldots, P_{\max }\right\} \mathrm{W}
\end{aligned}
$$

The number of states in the problem significantly affects the computational burden, but must be sufficient to allow accurate calculation of the cost function. Firstly, the speed and acceleration of the vehicle determine the electrical power consumption of the motor and therefore they must be included. The battery SoC must also be included in order to constrain the $\mathrm{SoC}$ within acceptable limits and protect the battery. Finally, the fuel cell power is included in order to penalise excessive load cycling and account for shut-down and start-up of the stack.

$$
S=S\left(a, v, \mathrm{SoC}, P_{F C}\right)
$$

The probability and cost matrices are generated using a reduced order model by simulating every valid action in every initial state. The subsequent state and associated cost of performing each action from each initial state is calculated from the simulation results. 
The MDP problem described is solved using SDP. The objective is to find the optimal control policy, $u=\pi^{*}(S)$ so as to minimise the total expected cost, $J_{\pi}\left(S_{0}\right)$, over an infinite horizon. Due to the inclusion of the terminal state, the solution should converge without the use of a discount factor. The total expected cost is calculated as;

$$
J_{\pi}\left(S_{0}\right)=\lim _{T \rightarrow \infty} E\left\{\sum_{t=0}^{T-1} C\left(S_{t}, \pi\left(S_{t}\right)\right)\right\}
$$

The optimal policy can be found using a policy iteration algorithm. This works by iteratively evaluating the current policy and then improving the policy until the total expected cost converges. The policy evaluation step (13), given the current control policy, $\pi$ is calculated as the cost incurred during the current step added to the expected cost of future steps given the new state, $S^{\prime}$, that the vehicle has transitioned to.

$$
J_{\pi}^{t+1}\left(S^{i}\right)=C\left(S^{i}, \pi\left(S^{i}\right)\right)+E\left\{J_{\pi}^{t}\left(S^{\prime}\right)\right\}
$$

The policy is then improved by finding the action which will minimise the total expected cost (14).

$$
\pi^{\prime}\left(x^{\prime}\right)=\underset{a \in A\left(S^{i}\right)}{\arg \min }\left[C\left(S^{i}, a\right)+E\left\{J_{\pi}\left(x^{\prime}\right)\right\}\right]
$$

This process is iterated until the solution converges to an acceptable tolerance level. The optimal policy $\pi^{*}(S)$ will be based on the state of the vehicle and time-invariant and therefore can be directly implemented for testing.

\section{Testing of Controller}

The optimal control policy obtained using SDP is entirely causal and time-invariant and therefore it is simple to implement in any simulation model using a 4-dimensional lookup table based on the vehicle state as defined in the MDP problem. This lookup table outputs the optimal action, i.e., Fuel Cell output power, based on the vehicle's speed and acceleration, the SoC of the battery and the previous DC/DC converter power demand. 


\section{Results}

The EMS developed using SDP has been simulated over a number of the logged drive-cycles, an example set of results is shown in Figure 2. This logged drive-cycle represents the typical start-stop usage pattern demonstrated by a postal delivery route on the university campus. The drive-cycle is approximately 1 hour long and constitutes of several individual trips separated by stationary periods. For the test vehicle, this results in an average power demand of only $0.3 \mathrm{~kW}$, and a maximum cruising power of $1.3 \mathrm{~kW}$, just within the capabilities of the fuel cell stack.

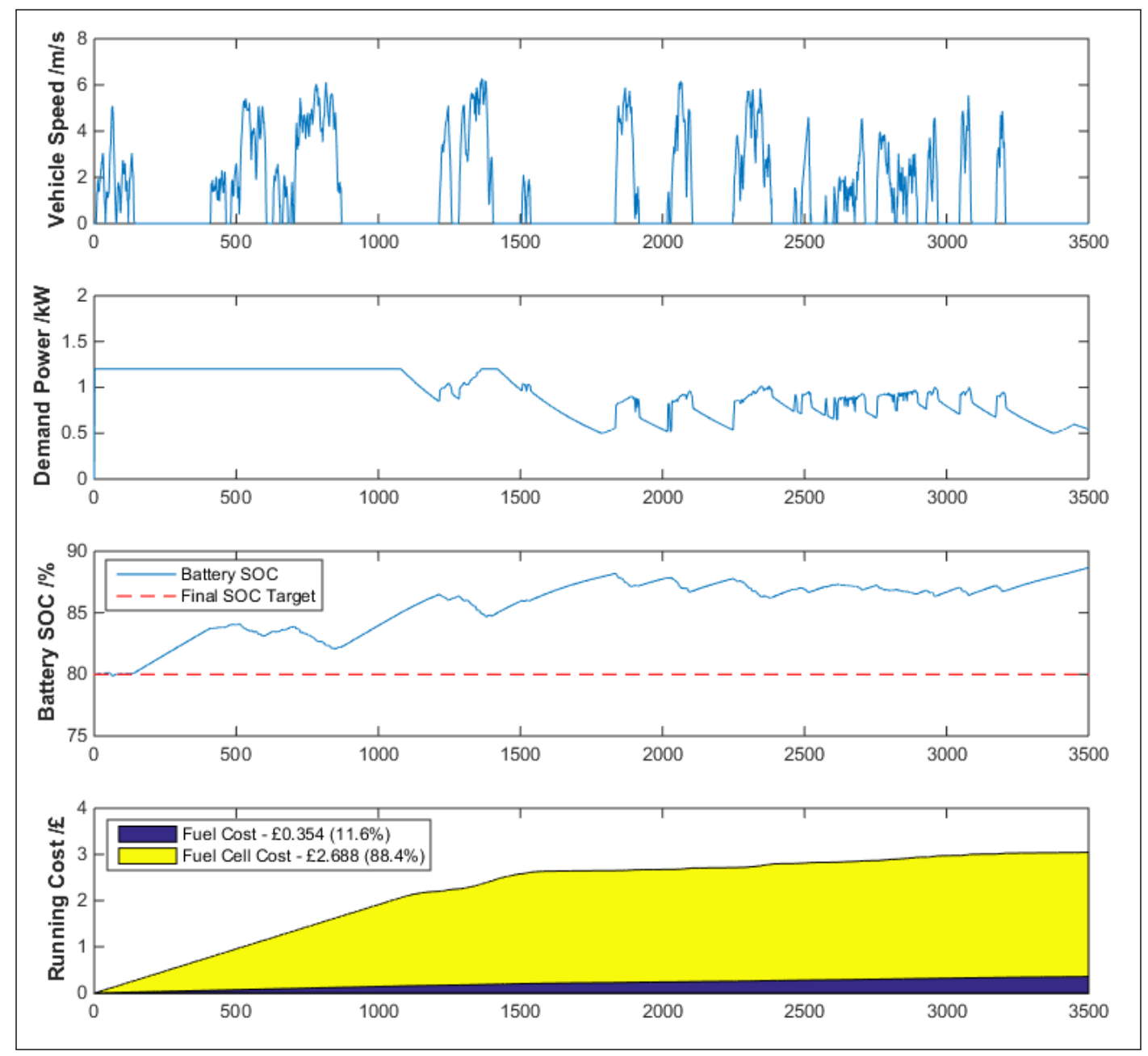

Figure 2: Accumulated running cost of MicroCab over 1 hour test cycle

\section{EMS Strategy Decisions}

It can be seen from Figure 2 that the EMS controller runs the fuel cell at maximum power for approximately the first 20 minutes of the test cycle even though the battery SoC is already above the final target. This results in a very high fuel consumption and very high degradation of the fuel cell. After this, the policy maintains a SoC of approximately $87 \%$, running the fuel cell at slightly higher power during times when the vehicle is moving. It is thought that the main reason for these strategy decisions is to prevent the battery voltage from dropping below the minimum acceptable voltage. At times when the vehicle is moving, the fuel cell runs at a higher power to partially offset the current draw from the motor. 


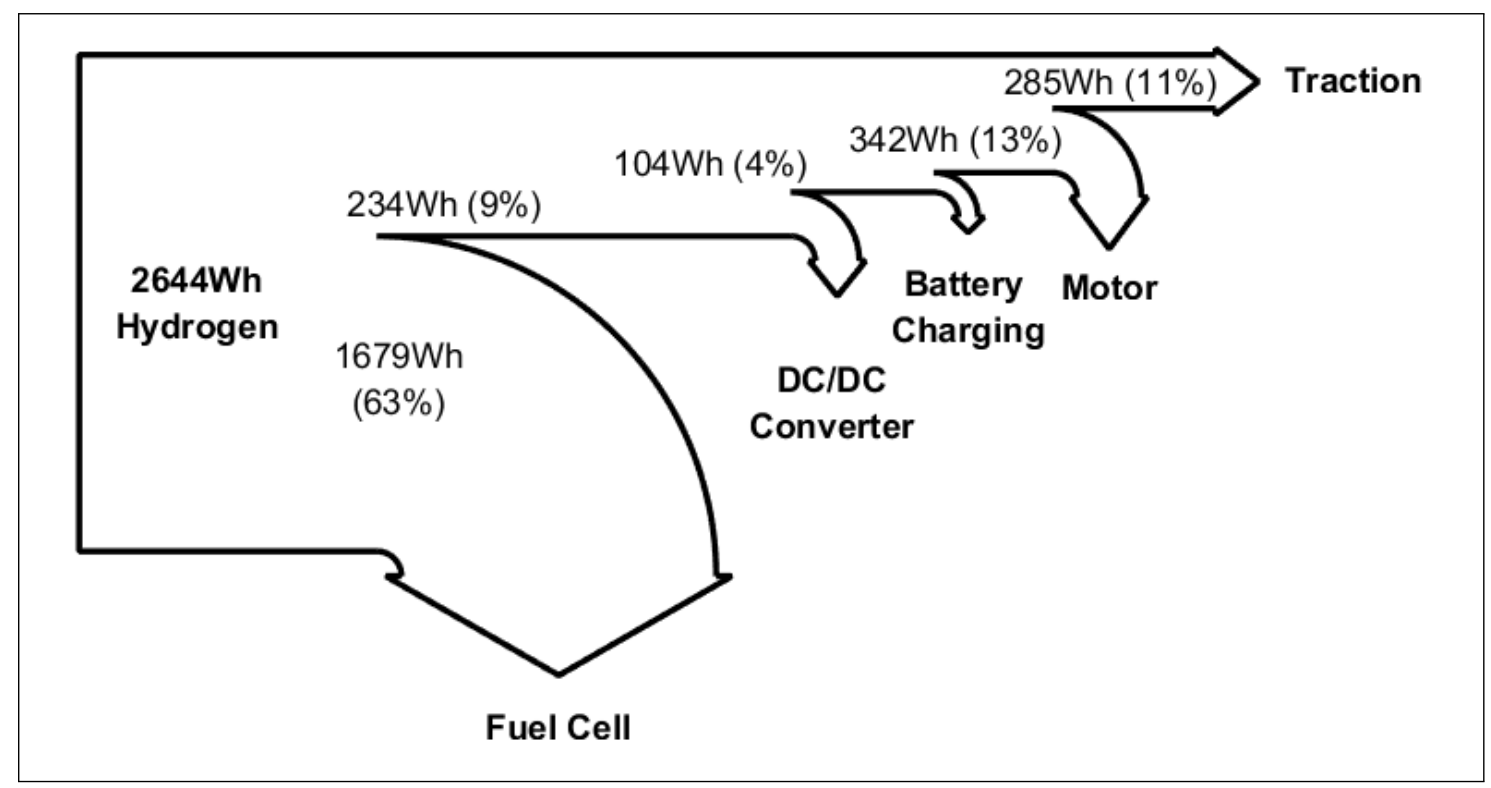

Figure 3: Sankey diagram showing the average efficiency over the drive-cycle

\section{Operating Efficiency}

Figure 3 is a Sankey diagram showing how the chemical energy in the fuel is used. It can be seen that the majority of energy (approx. 63\%) is lost in the conversion of the chemical energy in the fuel into electrical energy by the fuel cell. The next biggest energy loss $(13 \%)$ was to the power-train including the motor and drivetrain efficiencies. The DC/DC converter was responsible for approximately $9 \%$ of the energy loss and battery cycling represented $4 \%$. Overall only approximately $11 \%$ was used for tractive effort. These figures match up very well to the data collected by Iain Staffell et al. [39] at the University of Birmingham.

It can be seen that the SDP derived EMS controller does not noticeably improve on the overall operating efficiency of the vehicle. This is understood to be due to the small size of the fuel cell stack and therefore the limited control authority of the EMS taking into account constraints on the battery SoC deviation. In order to maintain acceptable battery voltage availability to run the motor over a typical usage pattern, even one with such a low average power requirement, the fuel cell must be run a high power levels, well outside of the optimal efficiency operating region. In addition to this, the potential gains from running the fuel cell at a more efficiency operating point are offset by the efficiency of the DC/DC converter which is less efficient at lower powers.

\section{Comparison of Fuel Cost vs. Degradation}

Both the fuel consumption and fuel cell degradation have been weighted by their approximate cost and therefore the accumulated cost over the simulation represents the estimated running cost of the journey.

Over the drive-cycle shown in Figure 2, the total cost of fuel was approximately $£ 0.35$, representing only $2.7 \%$ of the overall cost of the cycle. The fuel cell degradation due to degradation methods (4) and (5) is estimated at $£ 2.69$ representing a significantly higher contribution (20.6\%) to the running cost of the vehicle. Finally, although not shown the Figure 2, if the fuel cell is assumed to shut down after the test cycle is completed, the degradation due to start-up/shut-down 
cycling of the fuel cell is estimated at approximately $£ 10$, representing $76.6 \%$ of the running cost of the vehicle.

It must be noted that the EMS has been optimised based on the approximate cost of the fuel cell system as used in the vehicle, which was not mass produced. Toyota [40] estimate mass production to reduce the cost of their fuel cell stack to approximately $1 / 10$ th the cost of an individually produced stack. Even with this reduction, the estimated degradation cost would be $£ 1.62$, representing approximately $80 \%$ of the total running cost.

\section{Battery SoC Sustenance}

The Microcab does not incorporate an external charger for daily use, and therefore the EMS has been designed to be charge sustaining. The final SoC target has been set to $80 \%$, which is slightly higher than for a typical hybrid vehicle [27] because the vehicle does not yet have regenerative braking capabilities. Examination of the results in Figure 2 shows that the EMS has the tendency to overcharge above this target settling between $85 \%$ and $90 \%$ SoC.

Even though the battery $\mathrm{SoC}$ is initially at the required final SoC of $80 \%$, the EMS demands full power from the fuel cell for approximately the first 20 minutes of the test. This results in significant fuel use and degradation. It is thought that this is due to the fuel cell being slightly undersized for the application, and is therefore unable to sustain the battery SoC during long journeys. At approximately 700 seconds into the cycle, it can be seen that the battery SoC drops by approximately $2 \%$ during a short journey even though the fuel cell is running at maximum power throughout. This may lead to heavy penalties due to low battery SoC, and therefore the EMS is likely compensating for this by overcharging above the desired SoC.

\section{Conclusions}

A new charge sustaining EMS controller was successfully developed for the Microcab H4 which accounts for both the fuel consumption and the fuel cell degradation. The controller tends to charge the battery to a higher SoC than the terminal SoC set by the SDP cost function, which is thought to be due to the potential for the battery voltage to drop too low during accelerations at a lower SoC.

This means that the potential gains from implementing an SDP derived EMS controller on board the Microcab $\mathrm{H} 4$ are limited in regards to optimising the operating efficiency of the vehicle. It is shown that the constraints on the battery SoC and the limited power of the fuel cell mean that an optimal control policy that requires that the fuel cell is run a full power for a large proportion of the running time, similar to the original strategy on board the vehicle. As a result, the overall operating efficiency of the vehicle is relatively unchanged. 
The calculation of the total running cost of the fuel cell has produced an interesting result, however. The fuel cost, which is normally used to optimise the EMS, only represents $2.7 \%$ of the running cost of the vehicle. This is partly due to the requirement to run the fuel cell at a very high power for a significant proportion of the running time, but is also due to the high start/stop degradation as result of non-uniform distribution of fuel which would not be improved (and likely worsened) by using a larger fuel cell. This result shows EMS strategies for FCHEVs should include fuel cell degradation and that research into fuel cells should continue to focus on reliability and cost reduction.

T. Fletcher

December 2015

\section{Acknowledgements}

The authors would like to thank the Engineering and Physical Sciences Research Council (EPSRC) for providing funding for this for this project through the DTC in Hydrogen, Fuel Cells and Their Applications, Horiba-MIRA for providing funding and expertise and the department of Chemical Engineering at the University of Birmingham for the use of the Microcab H4 vehicles used for testing.

\section{Acronyms}

DDP Deterministic Dynamic Programming $\ldots \ldots \ldots \ldots \ldots \ldots 2$

DoE Department of Energy $\ldots \ldots \ldots \ldots \ldots \ldots \ldots \ldots \ldots \ldots \ldots \ldots \ldots \ldots \ldots$

ECASA $\quad$ Electro-Chemical Active Surface Area .................. 3

ECMS Equivalent Consumption Minimization Strategy .......... 2

EMS Energy Management Strategy ......................2

EPSRC Engineering and Physical Sciences Research Council......11

FCHEV Fuel Cell Hybrid Electric Vehicle...................... 1

ICE Internal Combustion Engine.......................

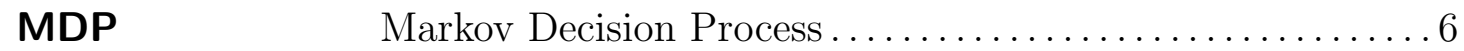

SDP Stochastic Dynamic Programming..................... 1

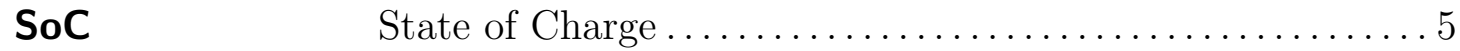

\section{References}

[1] H. Chen, P. Pei and M. Song, Applied Energy, 142, pp. 154 - 163 (2015).

[2] M. Dresselhaus, G. Crabtree and M. Buchanan, Office of Science, US Department of Energy (2004).

[3] R. Borup, J. Meyers, B. Pivovar, Y. S. Kim, R. Mukundan, N. Garland, D. Myers, M. Wilson, F. Garzon, D. Wood et al., Chemical reviews, 107(10), pp. 3904-3951 (2007). 
[4] X.-Z. Yuan, H. Li, S. Zhang, J. Martin and H. Wang, Journal of Power Sources, 196(22), pp. $9107-9116$ (2011).

[5] L. Placca and R. Kouta, International Journal of Hydrogen Energy, 36(19), pp. $12393-12405$ (2011).

[6] C.-C. Lin, H. Peng, J. W. Grizzle, J. Liu and M. Busdiecker, Control System Development for an Advanced-Technology Medium-Duty Hybrid Electric Truck, Technical Report 2003-01-3369, SAE (2003).

[7] M. Kim, Y.-J. Sohn, W.-Y. Lee and C.-S. Kim, Journal of Power Sources, 178(2), pp. $706-710(2008)$.

[8] M. Ansarey, M. S. Panahi, H. Ziarati and M. Mahjoob, Journal of Power Sources, 250, pp. 359 - 371 (2014).

[9] G. Fontaras, P. Pistikopoulos and Z. Samaras, Atmospheric Environment, 42(18), pp. $4023-4035$ (2008).

[10] C. Dextreit and I. V. Kolmanovsky, IEEE Transactions on Control Systems Technology, 22(99), pp. 652-663 (2013).

[11] L. Johannesson, M. Asbogard and B. Egardt, IEEE Transactions on Intelligent Transportation Systems, 8(1), pp. 71-83 (2007).

[12] E. D. Tate, J. W. Grizzle and H. Peng, International Journal of Robust and Nonlinear Control, 18(14), pp. 1409-1429 (2008).

[13] D. Opila, X. Wang, R. McGee, R. Gillespie, J. Cook and J. Grizzle, IEEE Transactions on Control Systems Technology, 20(6), pp. 1490-1505 (2012).

[14] S. Moura, J. Stein and H. Fathy, Control Systems Technology, IEEE Transactions on, 21(3), pp. 679-694 (2013).

[15] H. Zhang, Y. Qin, X. Li and X. Liu, in EIC Climate Change Technology Conference 2013, number 1569730735 in CCTC 2013 (2013).

[16] C. Vagg, Optimal Control of Hybrid Electric Vehicles for Real-World Driving Patterns, Ph.D. thesis, Department of Mechanical Engineering, University of Bath (2014).

[17] A. Rousseau, P. Sharer and R. Ahluwalia, Energy Storage Requirements for Fuel Cell Vehicles, Technical Report 2004-01-1302, SAE (2004).

[18] A. Schell, H. Peng, D. Tran, E. Stamos, C.-C. Lin and M. J. Kim, Annual Reviews in Control, 29(1), pp. 159 - 168 (2005).

[19] C.-C. Lin, M.-J. Kim, H. Peng and J. W. Grizzle, Journal of Dynamic Systems, Measurement, and Control, 128(4), pp. 878-890 (2006).

[20] F. G. Harmon, A. A. Frank and S. S. Joshi, Neural Networks, 18(56), pp. 772 -780 (2005).

[21] M. H. Cano, S. Kelouwani, K. Agbossou and Y. Dub, International Journal of Hydrogen Energy, 40(23), pp. 7260 - 7272 (2015). 
[22] J. Bauman and M. Kazerani, IEEE Transactions on Vehicular Technology, 57(2), pp. $760-769$ (2008).

[23] A. Brahma, Y. Guezennec and G. Rizzoni, in Proceedings of the 2000 American Control Conference, number 6 in 2000 American Control Conference, pp. 60-64 (2000).

[24] C.-C. Lin, H. Peng, J. Grizzle and J.-M. Kang, IEEE Transactions on Control Systems Technology, 11(6), pp. 839 - 849 (2003).

[25] V. H. Johnson, K. B. Wipke and D. J. Rausen, HEV Control Strategy for Real-Time Optimization of Fuel Economy and Emissions, Technical Report 2000-01-1543, SAE (2000).

[26] C. Musardo, G. Rizzoni, Y. Guezennec and B. Staccia, European Journal of Control, 11(4-5), pp. $509-524$ (2005).

[27] D. Sinoquet, G. Rousseau and Y. Milhau, Optimization and Engineering, 12, pp. 199-213 (2011).

[28] F. Vidal-Naquet and G. Zito, in Vehicle Power and Propulsion Conference (VPPC), 2012 IEEE, pp. 358-363 (2012).

[29] B. Baumann, G. Washington, B. Glenn and G. Rizzoni, Mechatronics, IEEE/ASME Transactions on, 5(1), pp. 58-72 (2000).

[30] R. Johri and Z. Filipi, in ICE2011 Conference (2011).

[31] C.-C. Lin, H. Peng and J. Grizzle, in Proceedings of the 2004 American Control Conference, volume 5, pp. $4710-4715$ (2004).

[32] J. T. Pukrushpan, H. Peng and A. G. Stefanopoulou, Control of Fuel Cell Power Systems, Springer (2008).

[33] S. Zhang, X. Yuan, H. Wang, W. Mrida, H. Zhu, J. Shen, S. Wu and J. Zhang, International Journal of Hydrogen Energy, 34(1), pp. 388 - 404 (2009).

[34] D. Liu and S. Case, Journal of Power Sources, 162(1), pp. 521 - 531 (2006).

[35] J. Sun and I. Kolmanovsky, Control Systems Technology, IEEE Transactions on, 13(6), pp. 911-920 (2005).

[36] J. Pukrushpan, A. Stefanopoulou and H. Peng, Control Systems, IEEE, 24(2), pp. 30-46 (2004).

[37] A. Vahidi, A. Stefanopoulou and H. Peng, IEEE Transactions on Control Systems Technology, 14(6), pp. 1047 -1057 (2006).

[38] Y. Shao, G. Yin and Y. Gao, Journal of Power Sources, 171(2), pp. 558 566 (2007).

[39] I. Staffell, International Journal of Electric and Hybrid Vehicles, 3(1), pp. 62-82 (2011).

[40] T. Yokoyama, in California Air Resources Board ZEV Symposium, Sacramento CA. Sept, volume 21 (2009). 